\title{
Corticosteroid therapy in nephrotic syndrome: a meta-analysis of randomised controlled trials
}

\author{
Elisabeth M Hodson, John F Knight, Narelle S Willis, Jonathan C Craig
}

\begin{abstract}
Aims-To determine the benefits and toxicity of different corticosteroid regimes in preventing relapse in steroid responsive nephrotic syndrome.

Design-Meta-analysis of randomised controlled trials.

Subjects-Twelve trials involving 868 children aged 3 months to 18 years.

Main outcome measure-Frequency of relapse.

Results-A meta-analysis of five trials, which compared two months of prednisone with three months or more in the first episode, showed that the longer duration significantly reduced the risk of relapse at 12-24 months (relative risk 0.73 ; $95 \%$ confidence interval 0.60 to 0.89 ) without an increase in adverse events. There was an inverse linear relation (relative risk 1.382 (SE 0.215) - 0.133 (SE 0.048) duration; $\left.r^{2}=0.66 ; \mathrm{p}=0.05\right)$ between the duration of treatment and risk of relapse. Conclusions-Children in their first episode of steroid responsive nephrotic syndrome should be treated with prednisone for at least three months, with an increase in benefit being shown for up to seven months of treatment.

(Arch Dis Child 2000;83:45-51)
\end{abstract}

Keywords: nephrotic syndrome; corticosteroid therapy; systematic review; meta-analysis

Corticosteroid therapy has been used in childhood nephrotic syndrome since the 1950s. Of children who present with their first episode, the majority of children have minimal change disease and $90-95 \%$ will respond to steroid therapy. ${ }^{12}$ With steroid therapy, mortality has fallen from $35 \%{ }^{3}$ to $3 \%{ }^{4}$ because of a reduction in serious infections. Because of this dramatic before-after evidence that corticosteroids improve the outcome of nephrotic syndrome, oral corticosteroids are the first line treatment of a child presenting with idiopathic nephrotic syndrome. No properly controlled prospective trials of corticosteroids compared to placebo were carried out.

Nephrotic syndrome is a potentially chronic disease with about $70 \%$ of patients suffering a relapsing course and being at risk of the adverse effects of steroid treatment. A standard prednisone regimen developed by the International Study of Kidney Disease in Children $(\text { ISKDC) })^{5}$ and the Arbeitsgemeinschaft für Pädiatrische Nephrologie (APN) ${ }^{6}$ for the initial attack is widely used. This consists of daily prednisone for four weeks followed by inter- mittent prednisone ${ }^{5}$ (three consecutive days out of seven) or alternate day prednisone ${ }^{6}$ for four weeks.

Using data from several multicentre studies, it has been recommended ${ }^{7} 8$ that the dose and duration of corticosteroid therapy should exceed that used in the standard regime. However, the optimal dose and duration of prednisone or other steroid agent that is most beneficial in maintaining remission and associated with least toxicity is not clear. The aim of this study is to assess the benefits and harms of corticosteroid therapy in the management of childhood nephrotic syndrome by conducting a systematic review and meta-analysis of randomised controlled trials. The information will assist clinicians in their decision making and identify to researchers questions that remain to be answered.

\section{Methods}

SEARCH STRATEGIES

Randomised and quasi-randomised trials of corticosteroid agents in steroid responsive nephrotic syndrome (SRNS) were identified from Medline (1966 to July 1998), Embase (1988 to July 1998), and the Cochrane Controlled Trials Register (Cochrane Library Issue 2, 1998). The databases were searched using optimally sensitive strategies for the identification of randomised controlled trials developed for the Cochrane Collaboration, ${ }^{9} 10$ combined with text words and subject headings for nephrotic syndrome, lipoid nephrosis, child, and steroid. Reference lists of review articles, relevant trials, nephrology textbooks, and proceedings of scientific meetings were also searched. Investigators known to be active in the field were also contacted to seek information about any unpublished trials.

\section{INCLUSION CRITERIA}

Titles were screened by one reviewer $(\mathrm{EH})$, who retained articles in which children with SRNS were treated with corticosteroid agents only. Abstracts were reviewed independently for study eligibility by two reviewers (EH, JK). Studies were selected if they were randomised or quasi-randomised trials, if they involved children aged 3 months to 18 years in their initial or subsequent episode of SRNS, ${ }^{11}$ if they compared different durations, total doses, or other dose strategies of prednisone or other corticosteroid agent, and if follow up data for six months or more were available. Studies involving children with steroid resistant nephrotic syndrome, congenital nephrotic syndrome, or nephrotic syndrome associated with other glomerulonephritides were excluded. 

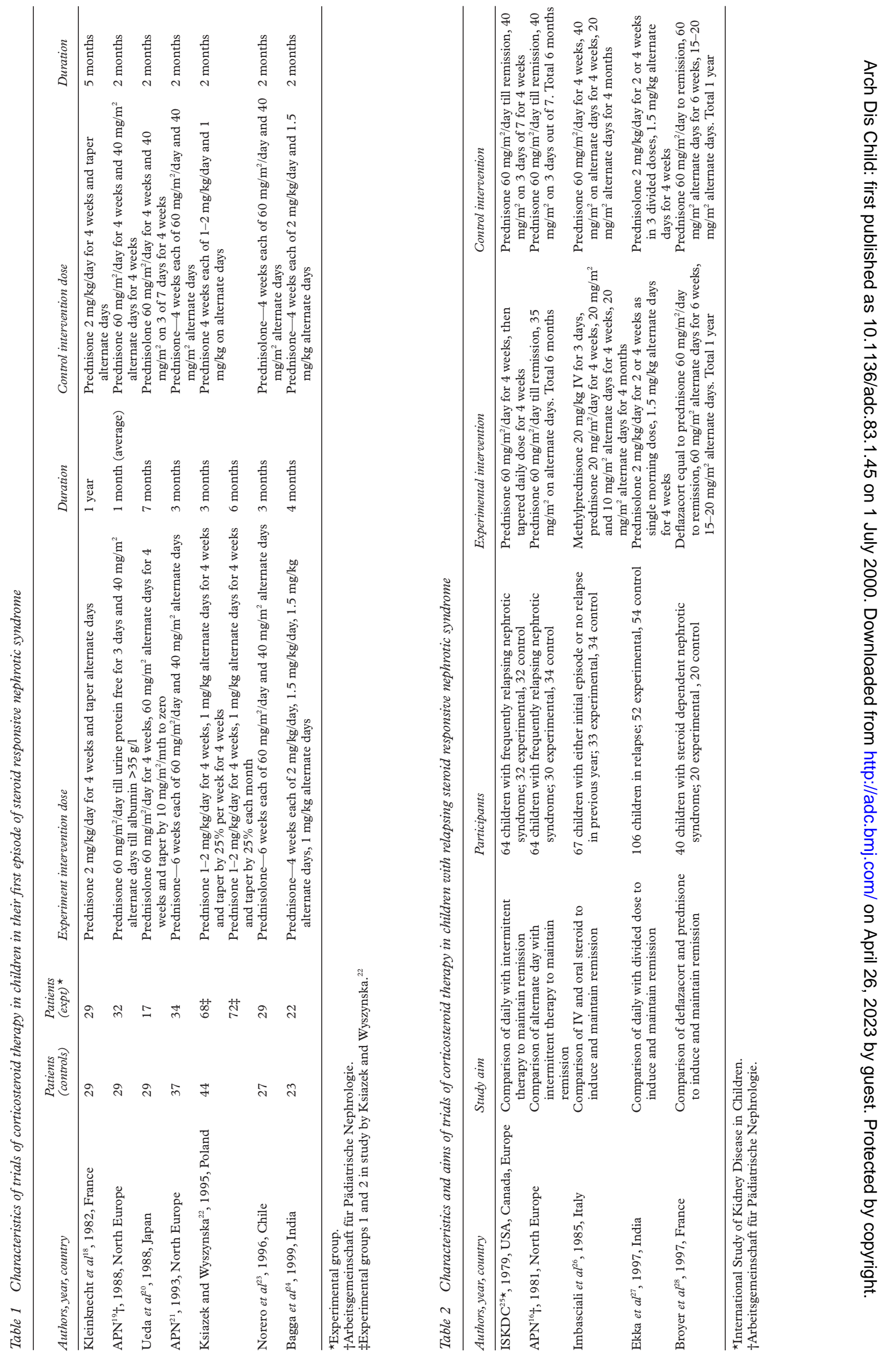
Table 3 Assessment of study quality in trials of corticosteroid therapy in children with steroid responsive nephrotic syndrome

\begin{tabular}{llllll}
\hline $\begin{array}{l}\text { Episode of } \\
\text { nephrotic } \\
\text { syndrome }\end{array}$ & Author and year & Allocation \\
concealment & $\begin{array}{l}\text { Intention } \\
\text { to treat } \\
\text { analysis }\end{array}$ & $\begin{array}{l}\text { Completeness } \\
\text { of follow } \\
\text { up }\end{array}$ & $\begin{array}{l}\text { Blinding of } \\
\text { outcome } \\
\text { assessment }\end{array}$ \\
\hline Initial & Kleinknecht et al, $1982^{18}$ & Adequate & No & E & No blinding \\
& APN, $1988^{19}$ & Adequate & No & A & No blinding \\
& Ueda et al, $1988^{20}$ & Inadequate & No & A & No blinding \\
& APN, $1993^{21}$ & Adequate & No & A & No blinding \\
& Ksiazek and Wyszynska, $1995^{22}$ & Inadequate & Yes & A & No blinding \\
& Norero et al, $1996^{23}$ & Inadequate & No & A & No blinding \\
Relapse & Bagga et al, $1999^{24}$ & Unclear & No & A & No blinding \\
& ISKDC, $1979^{25}$ & Unclear & No & D & No blinding \\
& APN, $1981^{16}$ & Inadequate & No & D & No blinding \\
& Imbasciali et al, $1985^{26}$ & Adequate & Yes & A & No blinding \\
& Ekka et al, $1997^{27}$ & Unclear & No & C & No blinding \\
& Broyer et al, $1997^{28}$ & Adequate & Yes & B & Double \\
& & & & & blind
\end{tabular}

${ }^{\star}$ Completeness of follow up: A, <3\% excluded; B, 3-9\% excluded; C, 10-19.9\% excluded; D, $20 \%$ or more excluded; E, unclear.

APN, Arbeitsgemeinschaft für Pädiatrische Nephrologie.

ISKDC, International Study of Kidney Disease in Children.

Studies reported in non-English language journals were translated before assessment. Where more than one publication of one trial existed, only the publication with the most complete data was included.

QUALITY ASSESSMENT

The quality of studies was assessed by two reviewers $(\mathrm{EH}, \mathrm{JK})$ without blinding to authorship using the method of Crowther and Henderson-Smart. ${ }^{12}$ Discrepancies were resolved in discussion with a third reviewer (JC). The quality items assessed were allocation concealment, intention to treat analysis, completeness of follow up, and blinding of outcome assessment because these are known to influence the true treatment effect. ${ }^{13}$

\section{DATA EXTRACTION}

Data extraction was carried out independently by two reviewers (EH, JK). Disagreements were resolved in consultation with a third reviewer (JC). The standard steroid regime advocated by ISKDC $^{5}$ and $\mathrm{APN}^{6}$ was compared with other regimes where possible. The primary outcome measure was the prevention of relapse as measured by the number of children with and without relapse at six months or more of the study. Secondary outcome measures sought were the number who developed frequently relapsing nephrotic syndrome, ${ }^{5}$ mean relapse rate per patient, mean length of time to next relapse, cumulative corticosteroid dosage, and adverse events (reduced growth rate, hypertension, cataracts, glaucoma, psychological disorders, infections, thromboses, osteoporosis).
STATISTICAL METHODS

For dichotomous outcomes the relative risks $(\mathrm{RR})$, risk differences (RD), and number needed to treat (NNT) for individual studies were calculated and summary effect measures calculated in $\operatorname{RevMan}^{14}$ using the random effects model. The random effects model takes into account the between study variability as well as the within study variability. A fixed effects model was also used to test for the robustness of the analysis and outliers. Heterogeneity was analysed using the $\chi^{2}$ test with an $\alpha$ of 0.1 used for statistical significance. Weighted mean differences (WMD) were calculated from pooled data for continuous scales of measurement. To ensure independence in trials with two or more experimental arms, only one experimental arm could be included in the analyses. As we wished to examine a wide range of doses and durations of therapy, we chose to include the experimental group with the longest duration of treatment when trials had more than one experimental arm. Examination of the effects of study quality, patient type (initial episode, relapsing), and different interventions was attempted by subgroup analysis. To determine whether RR was constant across studies or whether it varied depending on plausible effect modifiers such as dose and duration of treatment and the risk of relapse in the control group (control event rate), meta-regression was performed. ${ }^{15}$ For the analyses, the total dose of prednisone administered for induction of the first remission was calculated from the treatment protocol described.

\section{Results}

TRIAL CHARACTERISTICS

Of the 491 studies identified, 14 were identified by full text review to be randomised controlled trials. Two articles ${ }^{6}{ }^{16}$ were duplicate publications, so the article containing the most information ${ }^{16}$ was included. One $\operatorname{trial}^{17}$ in abstract form only was excluded as follow up data were only available to three months. One study $^{18}$ was available in abstract form only. Additional information on the results was not available from the investigators. Thus 12 trials involving 868 children were evaluated. Table 1 shows the characteristics of the seven trials ${ }^{18-24}$ in children in their initial episode of SRNS. Five trials ${ }^{20-24}$ compared standard therapy $(60$ $\mathrm{mg} / \mathrm{m}^{2} /$ day prednisone for four weeks followed by $40 \mathrm{mg} / \mathrm{m}^{2}$ on alternate days or on three conthree months or more of prednisone with two months therapy

\begin{tabular}{|c|c|c|c|c|c|}
\hline & $\begin{array}{l}\text { Number } \\
\text { of trials }\end{array}$ & $R R(95 \% C I) \dagger$ & $R D(95 \% C I) \dagger$ & $\begin{array}{l}N N T \\
(95 \% C I) \dagger\end{array}$ & $W M D(95 \% C I)$ \\
\hline Relapse by 6 months ${ }^{20-24}$ & 4 & $0.59(0.46,0.76)$ & $-0.27(-0.38,-0.16)$ & $4(2,6)$ & \\
\hline Relapse by $12-24$ months $^{20-24}$ & 5 & $0.73(0.60,0.89)$ & $-0.20(-0.31,-0.10)$ & $5(3,10)$ & \\
\hline No. frequent relapsers ${ }^{20-24}$ & 5 & $0.67(0.48,0.93)$ & $-0.13(-0.22,-0.03)$ & $8(5,33)$ & \\
\hline Mean relapse rate/pt/y $\mathrm{y}^{2024}$ & 3 & & & & $-0.31(-0.51,-0.12)$ \\
\hline Mean time to relapse (weeks) ${ }^{2024}$ & 2 & & & & $1.50(-0.75,3.75)$ \\
\hline Serious adverse events ${ }^{\star 20-24}$ & 5 & $0.89(0.56,1.41)$ & $-0.01(-0.12,0.09)$ & & \\
\hline Number with infections ${ }^{22} 23$ & 2 & $0.79(0.53,1.18)$ & $-0.09(-0.23,0.06)$ & & \\
\hline Cumulative steroid dose ${ }^{2324}$ & 2 & & & & $192(-2038,2421)$ \\
\hline
\end{tabular}

^Hypertension, psychological disorders, cataracts, glaucoma, reduced growth rate, thromboses, osteoporosis.

†Only the experimental treatment arm of six months duration from the trial of Ksiazek and Wyszynski ${ }^{22}$ has been included.

$\mathrm{RR}$, relative risk; RD, risk difference; NNT, number needed to treat; WMD, weighted mean difference. 


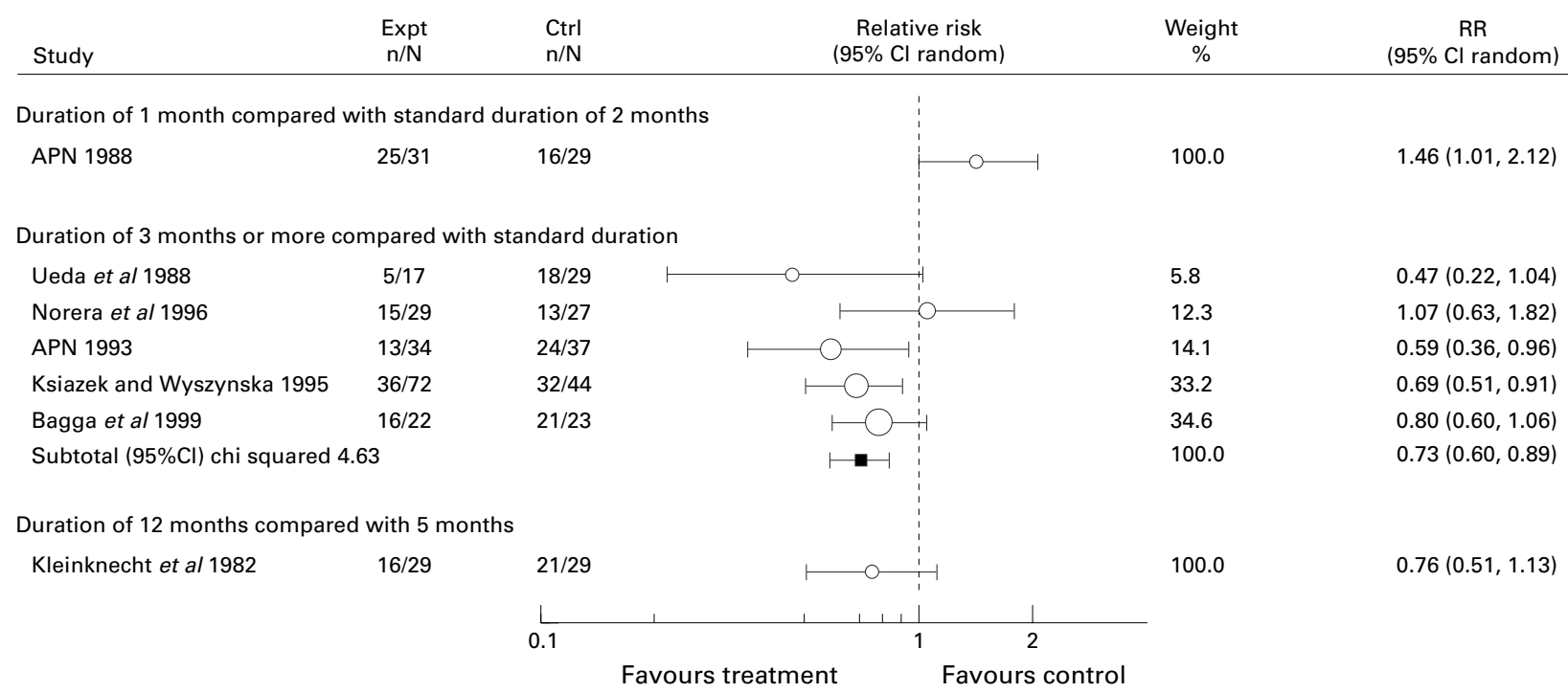

Figure 1 Meta-analysis of the relative risk (95\% CI) for relapse of nephrotic syndrome by 12-24 months in five trials (334 patients) of corticosteroid therapy in children with their first episode of nephrotic syndrome. Results are ordered by trial weights. Only the experimental arm of six months duration from Ksiazek and Wyszynski $i^{22}$ has been included. Also shown are the relative risks for relapse in the two other studies of corticosteroid therapy in children with their first episode of nephrotic syndrome.

secutive days out of seven for two months), with regimes of at least three months of therapy comprising 1-2 months of daily and 1.5-6 months of alternate day therapy. In one of these trials $^{22}$ standard therapy was compared with two experimental regimes. The outcomes from the experimental group treated for six months were included in the analyses. One of these trials $^{22}$ excluded those children who became steroid dependent. One trial ${ }^{19}$ compared standard therapy with a shorter duration of treatment and one trial ${ }^{18}$ compared five months with one year of therapy. Table 2 shows the aims and characteristics of five trials ${ }^{1625-28}$ in children with relapsing SRNS. Each study explored different treatment regimes aimed at inducing and/or maintaining remission.

STUDY QUALITY

Table 3 shows the assessment of study quality. Randomisation was adequately concealed in five studies. In two studies ${ }^{202}$ the numbers of children in the treatment and control groups differed considerably, and in the Polish study ${ }^{22}$ it was stated that the parents could influence which treatment group their child was assigned to. In the Japanese study ${ }^{20}$ the calculated total protocol dose $\left(4620 \mathrm{mg} / \mathrm{m}^{2}\right)$ exceeded the dose administered (3132 (SD 417) $\mathrm{mg} / \mathrm{m}^{2}$ ) suggesting that the protocol was not adhered to in all patients. Only three studies were analysed on an intention to treat basis. ${ }^{22} 26$ Fewer than $10 \%$ of participants were excluded in seven studies. ${ }^{19-2426}$ Only one study ${ }^{28}$ reported that outcome assessment was blinded. However, most studies reported the primary outcome measure using the ISKDC's definition of relapse. $^{5}$

OUTCOME OF CHILDREN IN THEIR FIRST EPISODE OF SRNS

Meta-analysis of the five studies ${ }^{20-24}$ involving 334 children, in which the experimental groups received a total calculated induction dose of prednisone of between 2922 and $4620 \mathrm{mg} / \mathrm{m}^{2}$ administered over three to seven months, showed that the longer durations and higher doses resulted in significant reductions in relapse rate, the number of relapses per patient per year, and the number of children who relapsed frequently (table 4 , fig 1 ). There was no increase in serious adverse events, infections, or cumulative steroid dose reported. No significant heterogeneity was shown (fig 1). Only one ${ }^{21}$ of the five studies showed adequate allocation concealment, so subgroup analysis based on study quality was not possible. A single study $^{20}$ showed that a total dose and duration less than the standard regime resulted in a significantly higher relapse rate at 12 months (RR 1.46; 95\% confidence interval (CI) 1.01 to 2.12 ) and a shorter time to first relapse (WMD -3.00; 95\% CI -4.94 to -1.06). A further single $\operatorname{trial}^{18}$ showed no evidence that the relapse rate was significantly reduced by giving prednisone for one year compared with five months (RR $0.76 ; 95 \%$ CI 0.51 to 1.13 ).

In the six studies ${ }^{19-24}$ comparing standard therapy with other doses and durations of therapy, there was no significant association between the rate of relapse in the control groups treated for only two months (control event rate) and the relative risk for relapse at $12-24$ months $\left(r^{2}=0.18, \mathrm{p}=0.4\right)$. Combining these six studies (fig 2) showed that the risk of relapse was significantly reduced with increased duration $(\mathrm{RR}=1.382 \quad(\mathrm{SE}$ $0.215)-0.133$ duration (SE 0.048); $r^{2}=0.66$; $\mathrm{p}=0.05)$ and dose (RR 1.701 (SE 0.292) 0.000264 dose (SE 8.630 $\mathrm{E}-05) ; \quad r^{2}=0.70 ;$ $\mathrm{p}=0.04)$ of prednisone. To explore whether duration or dose of prednisone determined the treatment response, we plotted the ratio of total dose to duration against relative risk (RR) to determine the average monthly dose (fig 3). This suggested that a reduction in risk of relapse was primarily associated with an increase in duration not dose, as an increase in 

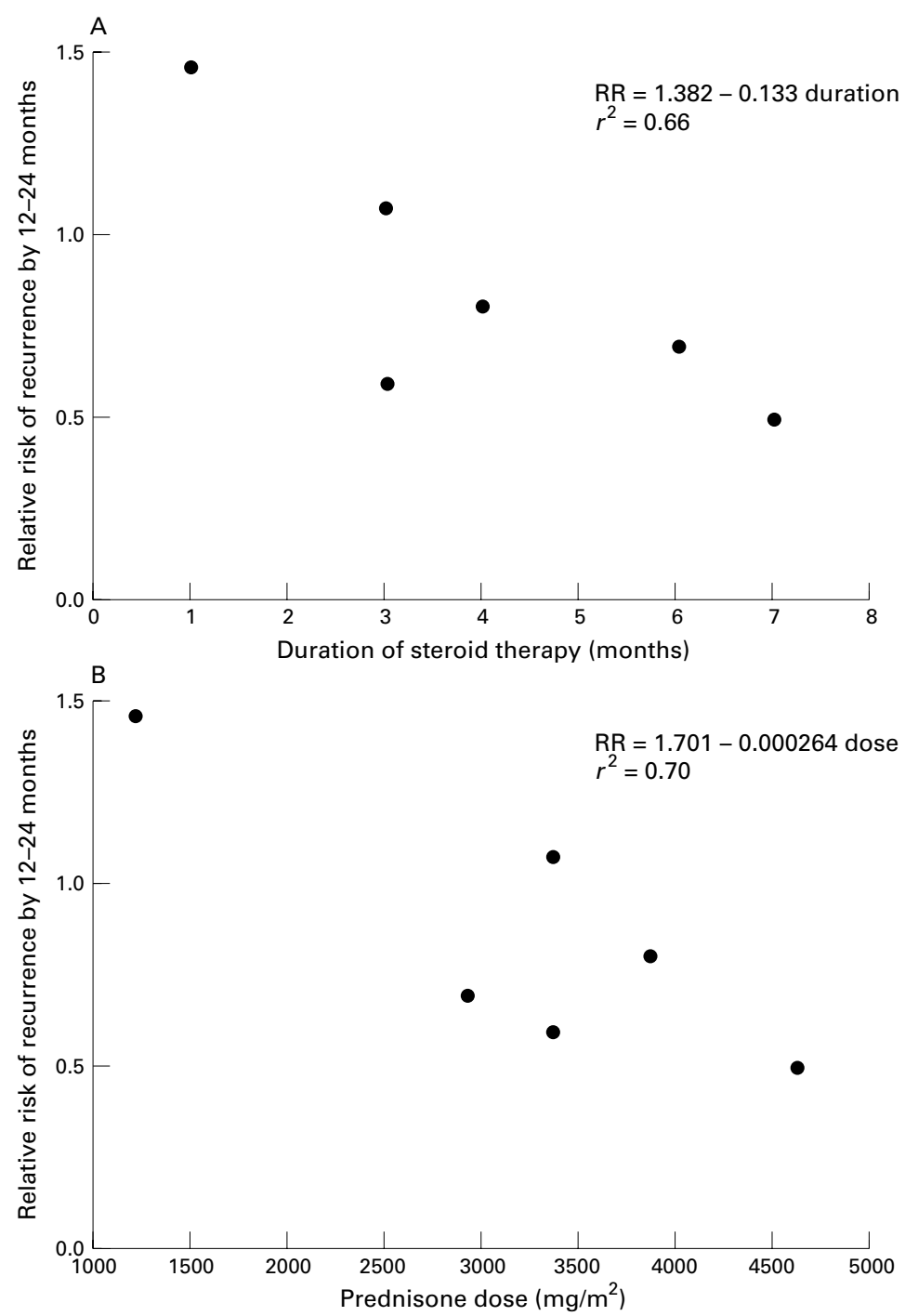

Figure 2 Relation between the risk of relapse by 12-24 months and the duration and dose of prednisone given to children in the first episode of steroid responsive nephrotic syndrome (six trials; 394 patients). Only the experimental arm of six months duration from Ksiazek and Wyszynski2 has been included.

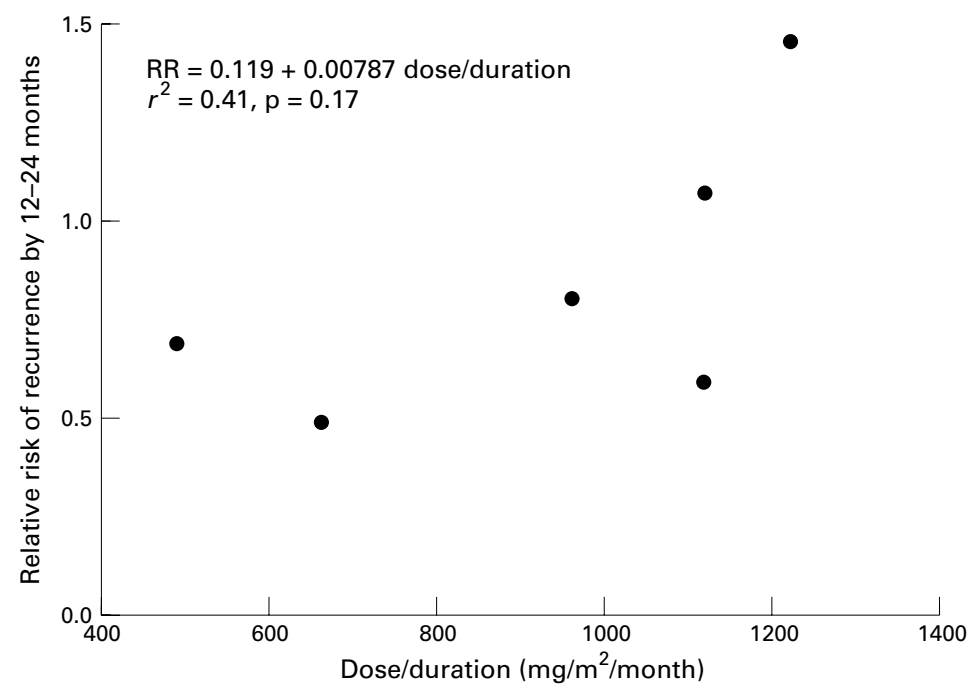

Figure 3 Relation between the risk of relapse by 12-24 months and the ratio of total dose to duration of treatment in children in the first episode of steroid responsive nephrotic syndrome (six trials; 394 patients). Only the experimental arm of six months duration from Ksiazek and Wyszynski ${ }^{22}$ has been included. dose per month appeared to be associated with increased rather than decreased relative risk for relapse.

CHILDREN WITH RELAPSING SRNS

Tables 2 and 5 show the characteristics and results of the studies ${ }^{1625-28}$ in children with relapsing SRNS. Alternate day therapy ${ }^{16}$ was significantly more effective than intermittent therapy in maintaining remission in frequently relapsing children during six months of therapy but there was no difference by 12 months. Single daily dosing ${ }^{27}$ was as effective as multiple daily dosing in achieving and maintaining remission in children who relapsed frequently. Deflazacort ${ }^{28}$ significantly reduced the number of children who relapsed during therapy and reduced the relapse rate among those who relapsed without significant differences in side effects. Comparison of therapeutic interventions used in children with their first episode of nephrotic syndrome with those used in children with relapsing nephrotic syndrome was not possible as no studies compared the same interventions in these different patient groups.

\section{Discussion}

Treatment of children in their first episode of SRNS with prednisone for between three and seven months compared with two months results in fewer children experiencing relapses within 12-24 months without a notable increase in adverse effects. In addition there is a linear dose-response relation between the risk of relapse and the duration and total induction dose of prednisone.

Examination of the relation between the risk for relapse and the ratio of dose to duration suggests that longer duration of treatment is more important than total dose in reducing the risk. The relative risk of relapse at 12-24 months falls by $0.133(13 \%)$ for every month increase in therapy to seven months (fig 2). Table 6 illustrates the relation between the duration of prednisone therapy and the relapse rate when treated for two months. The higher the relapse rate with two months of therapy (control event rate), the greater the magnitude of the treatment effect expected with increased durations of prednisone therapy. The control event rate in six studies ranged from $48 \%$ to $91 \%$ with a mean of $66 \%$. With relapse rate of $66 \%$ in children treated for two months, the event rate would fall by $9 \%$ for every increase by one month in the duration of therapy so that treatment for six months would reduce the risk of relapse by $36 \%(4 \times 9 \%)$ to $30 \%$ compared with two months. Ideally clinicians should know the control event rate in their local population so that they can determine how much increasing the duration of therapy will improve the outcome among their patients.

The treatment regime for the initial episode of SRNS was originally determined by the ISKDC. ${ }^{5}$ Subsequently the APN showed that alternate day therapy ${ }^{6}$ was more effective that intermittent administration in maintaining remission and that three months of therapy was more effective than two in preventing relapse. ${ }^{21}$ These data led to the recommendation that 
Table 5 Outcome of five trials of corticosteroid therapy in children with relapsing steroid responsive nephrotic syndrome

\begin{tabular}{|c|c|c|c|c|}
\hline Author, year & $\begin{array}{l}\text { Relapse on therapy, RR } \\
(95 \% \text { CI })\end{array}$ & $\begin{array}{l}\text { Relapse by } 9 \text { months, } \\
R R(95 \% \text { CI) }\end{array}$ & $\begin{array}{l}\text { Relapse by } 12 \text { months, } \\
\text { RR }(95 \% \text { CI })\end{array}$ & $\begin{array}{l}\text { Mean relapse rate during } \\
\text { study, WMD }(95 \% \mathrm{CI})\end{array}$ \\
\hline ISKDC, $1979^{25}$ & $0.20(0.05,0.82)$ & \multirow[t]{3}{*}{$1.00(0.89,1.12)$} & & $0.54(-0.50,1.58)$ \\
\hline APN, $1981^{16}$ & $0.60(0.36,1.02)$ & & $1.20(0.93,1.55)$ & $-0.20(-0.65,0.25)$ \\
\hline Imbasciali et al, $1985^{26}$ & & & $1.06(0.75,1.52)$ & \\
\hline Ekka et al, $1997^{27}$ & & \multirow[t]{2}{*}{$1.07(0.77,1.50)$} & & \\
\hline Broyer et al, $1997^{28}$ & & & $0.44(0.25,0.78)$ & $-1.90(-2.77,-1.03)$ \\
\hline
\end{tabular}

$\mathrm{RR}$, relative risk; WMD, weighted mean difference.

ISKDC, International Study of Kidney Disease in Children.

APN, Arbeitsgemeinschaft für Pädiatrische Nephrologie.

Table 6 Expected relapse rates of nephrotic syndrome in different groups of children at different risk of relapse after two months of prednisone

\begin{tabular}{lll}
\hline $\begin{array}{l}\text { Relapse rate } \\
\text { when treated for } \\
\begin{array}{l}\text { 2 months (\%) } \\
\text { Reduction in relapse rate }\end{array}\end{array}$ & $\begin{array}{l}\text { Relapse rate if treated } \\
\text { 1month }{ }^{\star} \text { of therapy } \\
\text { above 2 months (\%) }\end{array}$ & $\begin{array}{l}\text { for an additional } 5 \\
\text { months (total 7 } \\
\text { months) (\%) }\end{array}$ \\
\hline 80 & 11 & 25 \\
60 & 8 & 20 \\
40 & 5 & 15 \\
20 & 3 & 5 \\
10 & 1 & 5
\end{tabular}

${ }^{\star}$ Regression equation for duration of prednisone treatment: RR $=1.38-0.133$ duration.

children should receive six weeks of daily prednisone followed by six weeks of alternate day prednisone. ${ }^{7}$ Recently published recommendations $^{8}$ for initial treatment of nephrotic syndrome in children state that daily prednisone should be used for four to six weeks, followed by alternate day therapy for four to six weeks. However, neither of the authors based their conclusions on a systematic review and meta-analysis of the randomised trials included here.

In children with relapsing SRNS a single small study showed that the synthetic heterocyclic oxazoline glucocorticoid deflazacort ${ }^{28}$ maintained $66 \%$ more children with steroid dependent SRNS in remission during treatment in comparison with prednisone given in an equivalent dose. No significant increase in adverse events was shown but the study was underpowered to detect adverse events. Deflazacort may offer an alternative to prednisone for maintaining remission in children with steroid dependent SRNS. Further randomised controlled trials of deflazacort are required to confirm its efficacy. If deflazacort is confirmed to be more effective than prednisone, the benefits and toxicity of this medication in comparison with non-corticosteroid agents should be examined.

Study quality was generally poor with only five studies ${ }^{18} 19212628$ showing adequate allocation concealment. In only one $\mathrm{e}^{21}$ of the five studies included in the meta-analysis was allocation concealment considered adequate. Trials with inadequate allocation concealment can exaggerate the efficacy of the experimental treatment by $30-40 \%{ }^{13}$ and meta-analyses of low quality trials may overestimate the benefit of therapy. ${ }^{29}$ Despite these quality issues, no significant heterogeneity was shown and there was a consistent reduction in the number of children experiencing relapse with the longer duration of treatment.
Publication bias resulting from the exclusion of some unpublished trials cannot be totally excluded. Publication bias ${ }^{30}$ may result in an overestimate of treatment efficacy if the unpublished trials show no treatment effect. Formal testing using funnel plots or regression analysis was not possible because of the small number of studies. Responses from four senior investigators active in the field did not reveal any unpublished studies.

From the data, it was not possible to determine whether durations of treatment exceeding seven months would result in further reductions in the risk for relapse. No evidence of benefit through prolonging treatment to 12 months was shown in one study. ${ }^{18}$ Similarly the efficacy of total induction doses outside the range of doses used in the trials cannot be determined. No increase in toxicity was shown in the trials. However, individual trials were not designed specifically to study toxicity and so were underpowered for the detection of side effects of corticosteroids. Thus the low reported incidence of side effects with prolonged duration of corticosteroids could be explained by a type 2 statistical error and may not be generalisable to larger groups of children.

From this meta-analysis of randomised controlled trials it can be concluded that children in their first episode of nephrotic syndrome should be treated for at least three months, with an increase in benefit being shown for up to seven months of treatment. In a population with a baseline risk for relapse of $60 \%$ with two months of prednisone, daily prednisone for four weeks followed by alternate day therapy for six months would be expected to reduce the number of children experiencing a relapse by about $40 \%$.

This work was supported by the Australian Kidney Foundation. The authors wish to thank Professors Barratt, Brodehl, Broyer, and Ponticelli for responding to our requests for information about unpublished trials. This work has been presented in part at the 35th Annual Scientific Meeting of the Australian and New Zealand Society of Nephrology (Brisbane, 1999), the Annual Scientific Meeting of the Royal Australasian College of Physicians (Melbourne, 1999), and the 33rd Annual Meeting of the European Society for Paediatric Nephrology (Prague, 1999).

1 Anonymous. The primary nephrotic syndrome in children. Identification of patients with minimal change nephrotic syndrome from initial response to prednisone. A report of the International Study of Kidney Disease in Children. $\mathcal{F}$ Pediatr 1981;98:561-4.

2 Koskimies O, Vilska J, Rapola J, Hallman N. Long-term outcome of primary nephrotic syndrome. Arch Dis Child 1982;57:544-8.

3 Arneil GC. The nephrotic syndrome. Pediatr Clin North Am 1971;18:547-59.

4 Anonymous. Minimal change nephrotic syndrome in children: deaths during the first 5-15 years' observation. A report of the International Study of Kidney Disease in Children. Pediatrics 1984;73:497-501. 
5 Abramowicz M, Barnett HL, Edelmann CM Jr, et al. Controlled trial of azathioprine in children with nephrotic syntrolled trial of azathioprine in ch
drome. Lancet 1970;1:959-561.

6 Anonymous. Alternate-day versus intermittent prednisone in frequently relapsing nephrotic syndrome. A report of "Arbeitsgemeinschaft für Pädiatrische Nephrologie". Lancet 1979;1:401-3.

7 Brodehl J. The treatment of minimal change nephrotic syndrome: lessons learned from multicentre co-operative studies. Eur F Pediatr 1991;150:380-7.

8 Bargman JM. Management of minimal lesion glomerulonephritis: evidence-based recommendations. Kidney Int Suppl 1999;70:S3-16.

9 Dickersin K, Scherer R, Lefebvre C. Identifying relevant studies for systematic reviews. BMf 1994;309:1286-91.

10 Lefebvre C, McDonald S. Development of a sensitive search strategy for reports of randomized controlled trials in EMBASE. Paper presented at the Fourth International Cochrane Colloquium, Adelaide, Australia, 20-24 October 1996.

11 Anonymous. Early identification of frequent relapsers among children with minimal change nephrotic syndrome. A report of the International Study of
Children. $₹$ Pediatr 1982;101:514-18.

12 Crowther CA, Henderson-Smart DJ. Phenobarbital prior to preterm birth (Cochrane Review). In: The Cochrane Library, Issue 2. Oxford: Update Software, 1998

13 Schulz KF, Chalmers I, Hayes RJ, Altman DG. Empirica evidence of bias. Dimensions of methodological quality associated with estimates of treatment effects in controlled trials. $\mathcal{F A} M A$ 1995;273:408-12.

14 Review Manager (RevMan) 3.1 for Windows. Oxford: The Cochrane Collaboration, 1998 .

15 Lau J, Ioannidis JP, Schmid CH. Quantitative synthesis in systematic reviews. Ann Intern Med 1997;127:820-6.

16 Anonymous. Alternate-day prednisone is more effective than intermittent prednisone in frequently relapsing nephrotic syndrome. A report of "Arbeitsgemeinschaft für rotic syndrome. A report of "Arbeitsgemeinschaft fur
Pädiatrische Nephrologie". Eur f Pediatr 1981;135:229-37.

17 Hiraoka M, Sudo M. Low versus standard dosage of prednisolone for initial treatment of idiopathic nephrotic prednisolone for initial treatment of in children. In: Proceedings of the American Society syndrome in children. In: Proceedings of the A

18 Kleinknecht C, Broyer M, Parchoux B, Loriat C, Nivet H, Palcoux JB, Ami-Moussa R. Comparison of short and long treatment at onset of steroid sensitive nephrosis (SSN). Preliminary results of a multicenter controlled trial from the French Society of Pediatric Nephrology. Int 7 Pediatr Nephrol 1982;3:45.
19 Anonymous. Short versus standard prednisone therapy for initial treatment of idiopathic nephrotic syndrome in children. A report of "Arbeitsgemeinschaft für Pädiatrische Nephrologie". Lancet 1988;1:380-3.

20 Ueda N, Chihara M, Kawaguchi S, et al. Intermittent versus long-term tapering prednisolone for initial therapy in children with idiopathi

21 Ehrich JH, Brodehl J. Long versus standard prednisone therapy for initial treatment of idiopathic nephrotic syndrome in children. A report of "Arbeitsgemeinschaft für Pädiatrische Nephrologie”. Eur F Pediatr 1993;152:357-61.

22 Ksiazek J, Wyszynski T. Short versus long initial prednisone treatment in steroid-sensitive nephrotic syndrome in children. Acta Paediatr 1995;84:889-93.

23 Norero C, Delucchi A, Lagos E, Rosati P. Initial therapy of primary nephrotic syndrome in children: evaluation in a period of 18 months of two prednisone treatment schedules. Chilean Co-operative Group of Study of Nephrotic Syndrome in Children. Rev Med Chil 1996;124:56772 .

24 Bagga A, Hari P, Srivastava RN. Prolonged versus standard initial prednisolone therapy for initial episode of nephrotic syndrome. Pediatr Nephrol 1999;13:824-7.

25 Anonymous. Nephrotic syndrome in children: a randomized trial comparing two prednisone regimens in steroidresponsive patients who relapse early. Report of the International Study of Kidney Disease in Children. 7 Pediatr 1979;95:239-43.

26 Imbasciati E, Gusmano R, Edefonti A, et al. Controlled trial of methylprednisolone pulses and low dose oral prednisone for the minimal change nephrotic syndrome. $B M \mathcal{F}$ 1985;291:1305-8.

27 Ekka BK, Bagga A, Srivastava RN. Single- versus divideddose prednisolone therapy for relapses of nephrotic syndrome. Pediatr Nephrol 1997;11:597-9.

28 Broyer M, Terzi F, Lehnert A, Gagnadoux MF, Guest G, Niaudet P. A controlled study of deflazacort in the treatment of idiopathic nephrotic syndrome. Pediatr Nephrol 1997;11:418-22.

29 Moher D, Pham B, Jones A, et al. Does quality of reports of randomised trials affect estimates of intervention efficacy reported in meta-analyses? Lancet 1998;352:609-13.

30 Egger M, Davey-Smith G, Schneider M, Minder C. Bias in meta-analysis detected by a simple graphical test. $B M \mathcal{F}$ 1997;315:629-34. 